\title{
Thermal Energy Recovery through Optimal Salt concentration in a Parabolic Trough Systems
}

\author{
Rikesh Ramsurn ${ }^{1}$, and Aravind $\mathrm{CV}^{1, *}$ \\ School of Engineering, Taylor's University, Malaysia.
}

\begin{abstract}
Making a PVT system hybrid is to support the use of thermal and electrical energy simultaneously or independently, to control the thermal effect to improve electrical efficiency or vice-versa. This project makes use of the Parabolic Trough design with emphasis on making the system to be sustainable and also increasing the thermal efficiency of the system. Polystyrene and acrylic foam is utilized to maximize the heat retention capability of the system. To power, the pump that moves the heat transfer fluid (tested with salt water proportions) within the copper tube, a set of solar PV panel is to support its power demand making it sustainable. The closed loop setup designed achieved an improved thermal efficiency level of $66.2 \%$, which contributes to having a reliable heat energy source for applications such as hot showers. The novel setup design also makes use of PV cells to support other energy demands through power electronic control designs. Using a similar heat dissipation technique, a novel setup has been designed to improve the voltage supply by making use of liquid cooling and translucent glass PV panels. Cooling the PV panel restored up to $11.7 \%$ of its rated voltage supply. This is achieved by keeping the PV panels within its best thermal operating conditions using an energy efficient electronically controlled cooling system.
\end{abstract}

\section{Introduction}

Solar energy is considered as the cleanest and most abundant source of renewable energy harvested from sunlight [1]-[3]. Its net input to Earth is considered as 8000 times the rate of fossil and nuclear fuels currently being used by humanity on a worldwide scale. Methods of harvesting solar energy vary a lot in design but are essentially made up of photovoltaic cells when it comes to generating electricity. Due to its solid-state nature, silicon-based PV cells have an expectancy of operating for an indefinite amount of time without wearing out [4]. However, the efficiency of PV cells is still subjected to research and development with the aim of achieving sustainability in terms of electricity generation and consumption. The efficiency of PV cells is known to be affected by heat during its exposure to solar radiation while in operation. Hence methods are being devised to improve the efficiency of PV cells through heat dissipation [5]. With energy sustainability in mind, the heat dissipated is reused for applications with heat demand such as a hot water supply.

${ }^{1}$ Corresponding author: aravindcv@ieee.org 
A popular design currently being researched and developed for solar energy harvesting is the Parabolic Trough PVT design. Using light concentration concept, such as concentrating sunlight on an object using a magnifying glass causing it to melt or burn, the Parabolic Trough PVT design consists of a reflective sheet of metal (e.g. stainless steel) bent into a circular shape in order to reflect light rays from the sun onto a line of incidence [6]. The main application of this line of incidence is to convert the concentrated light rays into heat energy, thus contributing to the thermal aspect of the PVT design. Heat energy is collected by a copper pipe placed at the line of incidence of the reflected light rays. The heat energy collected is then be used for applications such as a hot water shower by transferring the heat to a water tank using a closed loop fluid flow circuit and a heat exchanger. The closed loop may contain water or other fluids which is facilitated faster and more efficient heat removal from the copper pipe and heat transfer to the water tank through the heat exchanger.

Following the heat dissipation concept, there is a possibility of improving the electrical efficiency of PVT systems by removing the heat build-up on PV panels/cells while reusing the heat for thermal applications. This improvement is brought through the restoration of the voltage supply which normally drops as the temperature of the panels rises [7]. A cooling technique which may be used to cool PV cells is the use of heatsinks. The heat build-up on the PV cells is transferred to the heatsinks through conduction while the latter may be air-cooled or liquid-cooled. The cooling method used may vary depending on the type of PV panel used and how the heat shall be reused [8]. Hence, it is important to further investigate and develop PVT systems such as the Parabolic Trough to achieve reliability and sustainability. In this work, a parabolic concentrating trough is experimentally studied and performance evaluated with phase layered heat removal strategy.

\section{Methodology}

\subsection{Experimental System Setup}

Heat Transfer Fluids (HTF) used in this research includes water, water with $10 \mathrm{~g} / \mathrm{L}$ of salt and water with $20 \mathrm{~g} / \mathrm{L}$ of salt. Figure 1 shows the flowchart of the system's thermal optimization implemented and experimented. The most important feature of the thermal optimization implemented is the use of a closed loop HTF circuit which involves the use of a copper coil heat exchanger for effective heat dissipation and a pump for liquid movement around the circuit. The size of the copper heat exchanger is selected according to the container size it will be in. The maximum volume the heat exchanger occupy in the container favour more effective heat dissipation. As for the pump, its specification depend on the amount of liquid to be moved around the circuit as well as the flow rate at which it shall be moved. Effective heat dissipation in a closed loop circuit requires in-depth flow rate calibration. For the experiments conducted during this research, flow rate calibration is performed experimentally by controlling the DC pump's voltage. The lower the voltage, the slower the flow rate and vice versa. Thermocouples are used to measure the various temperatures involved in this research. Experiments are conducted for each HTF for around 30 minutes under a specific weather or until the system reached a thermal settling point for the meteorological conditions, it is being experimented under. The closed loop is flushed with clean water before testing with each HTF. The recorded data are then analysed graphically. The principle of operation of the Phase Layered Heat Removal for thermal efficiency improvement is as demonstrated in Fig. 1. 


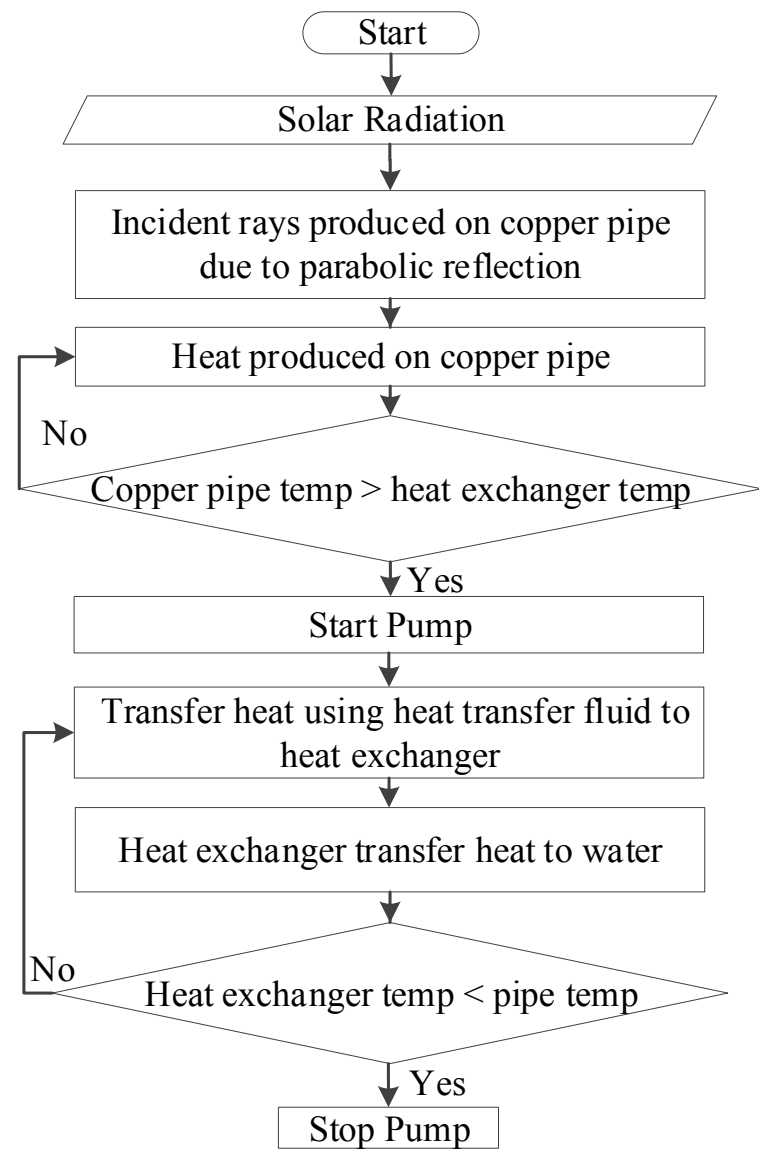

Fig. 1. Closed loop heat transfer topology.

\subsection{Electrical Characteristics Study}

When it comes to the electrical aspect, the cooling methods can either be active or passive. The advantage of active cooling is that it is rather faster than passive cooling. However, active cooling also affects the electrical efficiency with its power requirement [9]. Hence, the setup designed for this research is a combination of the two, whereby electricity is used by the cooling system only under specific conditions. The type of solar panel used for this research is a Silicon Thin Film of 20\% Transparency. The cooling design concept involves placing the panel in between two layers of liquid for the top and bottom surface heat removal. The cooling setup designed is connected as a closed loop, making use of a pump and a heat exchanger, or as an open loop connected to the main water supply pipe of the house or building where the system is placed. As an open loop setup, electronically controlled valves are used to control the liquid flow in case the flow from the mains is not enough to cool the panel, which in case a backup water tank is used to make up for the flow through gravitational difference. 


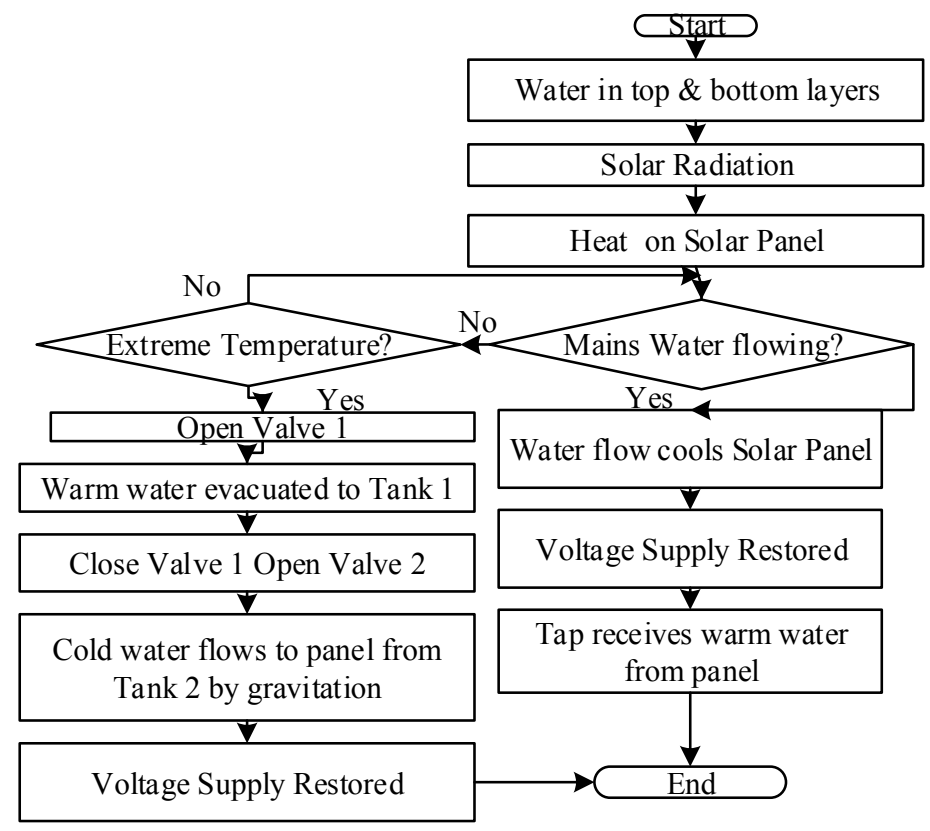

Fig. 2. Open loop heat removal topology.

The heat transfer topology for closed loop is similar to the one shown in Fig. 1 where the heat is produced on the panel instead of a copper pipe. For the open loop setup, the heat removal topology is as shown in Fig. 2. The PV panel cooling technique demonstrated by Fig. 2 is implemented at Taylor's University by connecting the water tap from the Engineering Workshop to the panel's inlet. The panel's outlet replaced the role of the water tap. The PV panel is placed under the sun and started heating up. Whenever a student is to use the water tap, the water from the tap flow into the panel's cooling layers to cool the panel. The heat from the panel is transferred to the water and leave the panel's cooling layers as warm water which the student using the tap could use. A warm water supply is appreciated at the Engineering Workshop for washing hands better than with cold water. If ever the panel's temperature get too high, an electronically controlled valve is opened to evacuate the hot water into a backup tank for later usage. The same principle is applied to a home or any other building with a water supply. While the panels are cooled, warm water is also being produced for instant use or to be stored for later usage. Fig. 3 shows the cooling setup design concept.

\begin{tabular}{|cc|}
\hline Top Cooling Layer \\
\hline \hline Bottom Cooling Layer \\
\hline
\end{tabular}

Fig. 3. Top and bottom liquid containers made of Perspex for layered cooling. 


\section{Results and Discussion}

\subsection{Thermal Efficiency}

The general equation for instantaneous thermal efficiency $\eta_{T}$ is as shown in Eq. 1 [3].

$$
\eta_{T}=F_{R}\left(n_{o^{-}} \frac{U_{L}}{C}\left(\frac{T_{\text {out }}-T_{\text {air }}}{G_{b}}\right)\right.
$$

Using Eq. 1 and experimental or simulation results obtained for optical efficiency [8] and heat loss coefficient [10] of the parabolic trough design, the instantaneous thermal efficiency for this research's PVT system has been derived and simplified into Eq. 2.

$$
\eta_{T}=0.667074-4.124820\left(\frac{T_{\text {out }}-T_{a i r}}{G_{b}}\right)
$$

Where $\eta_{\mathrm{T}}=$ instantaneous thermal efficiency; $F_{R}=$ heat removal factor; $\mathrm{n}_{\mathrm{o}}=$ optical efficiency; $\mathrm{U}_{\mathrm{L}}=$ overall heat loss coefficient, $\mathrm{W} / \mathrm{m}^{2} . \mathrm{K} ; C=$ concentration ratio; $\mathrm{T}_{\text {out }}=$ temperature of HTF leaving heat exchanger, $\mathrm{K} ; \mathrm{T}_{\mathrm{air}}=$ ambient temperature, $\mathrm{K} ; \mathrm{G}_{\mathrm{b}}=$ direct solar radiation, $\mathrm{W} / \mathrm{m}^{2}$.. Figure 4 to Figure 8 show the graphical results of the experiments conducted using the different HTFs and insulation.

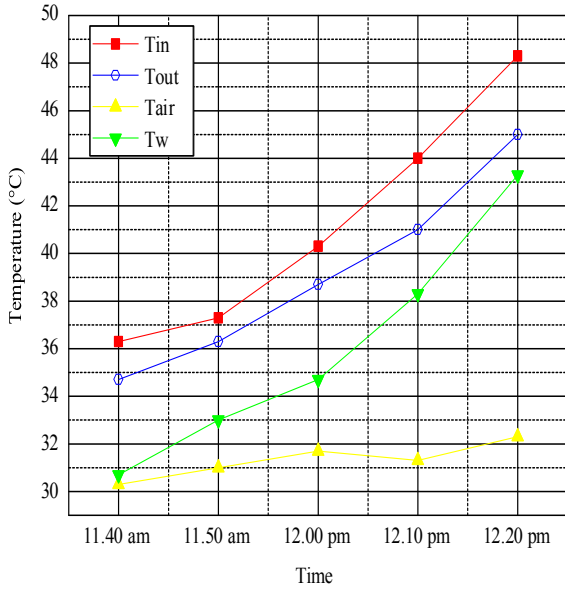

Fig. 4. Water as HTF.

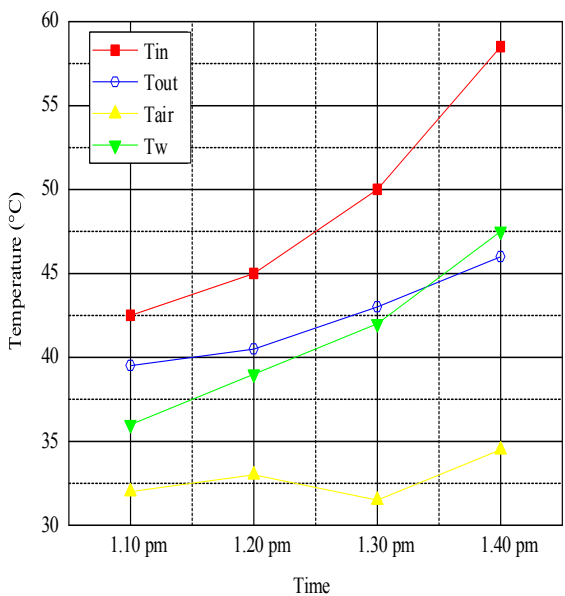

Fig. 6. Salt water at $20 \mathrm{~g} / \mathrm{L}$ as HTF.

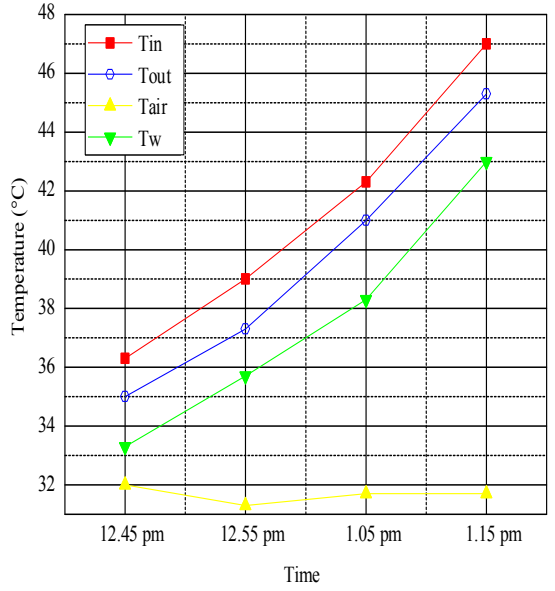

Fig. 5. Salt water at $10 \mathrm{~g} / \mathrm{L}$ as HTF.

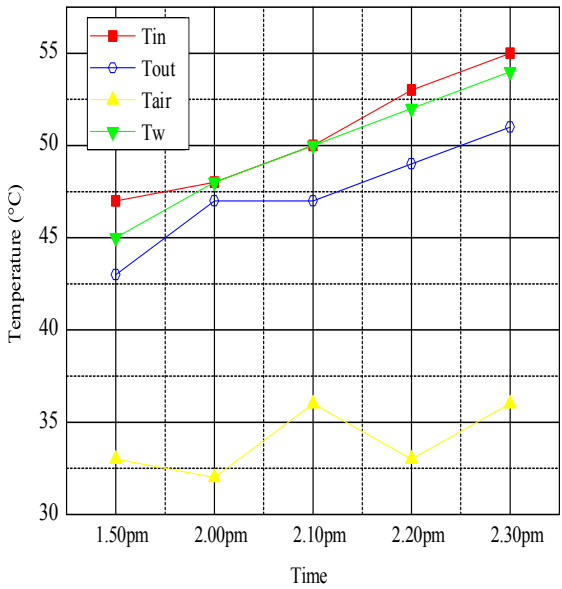

Fig.7. Salt water at $20 \mathrm{~g} / \mathrm{L}$ as HTF with polystyrene as pipe insulation. 


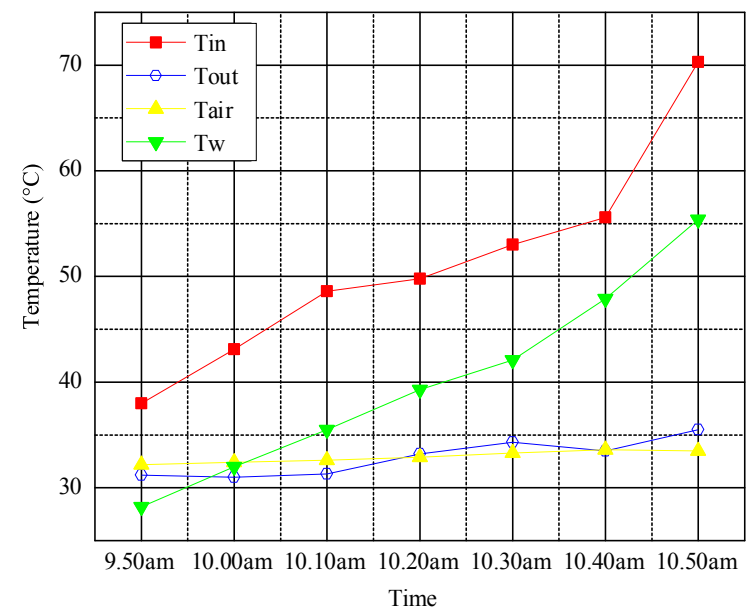

Fig. 8. Saltwater at $20 \mathrm{~g} / \mathrm{L}$ as HTF with acrylic foam as pipe insulation.

As seen from Fig. 4, water produces some appreciable results as an HTF but still is not good enough since it is observed from the graph that $T_{\text {in }}$ and $T_{\text {out }}$ are quite close. This indicates that the rate of heat transfer to the water in the tank is not that favorable. The results as shown in Fig. 5 demonstrate that Salt Water at $10 \mathrm{~g} / \mathrm{L}$ performs almost similarly as water thermally when compared to the results of water as HTF as seen in Fig. 4. It is observed that Salt Water at $20 \mathrm{~g} / \mathrm{L}$ is able to achieve much higher input temperatures as compared to water and the $10 \mathrm{~g} / \mathrm{L}$ salt solution. The temperature of the HTF leaving the heat exchanger is much lower, indicating good heat transfer properties of the liquid. From Fig. 7 and Fig. 8, the temperature of the water inside the tank quickly rises to the temperature of the HTF entering the heat exchanger. This indicates that the polystyrene and acrylic insulations helped reduce some heat loss from the copper pipe and hence the HTF flows with more heat capacity to be released into the water having a lower temperature. It is also observed that the temperature of the HTF leaving the heat exchanger is lower than the temperature of water, indicating that the salt water is able to transfer the heat to the water effectively. Almost all the graphs for the different configurations show a similar trend where $T_{\text {air }}$ remains relatively constant throughout the experiment while $T_{\text {in }}$, $\mathrm{T}_{\text {out, }}$ and $\mathrm{T}_{\mathrm{w}}$ continue to increase as the time goes by in the presence of the sun. $\mathrm{T}_{\text {out }}$ is always lower than $T_{\text {in }}$ and $T_{w}$. This is because as the water enters the heat exchanger, the heat is absorbed by the water inside the tank causing $T_{w}$ to increase while temperature leaving the heat exchanger decreases. Therefore, $T_{\text {out }}$ is always lower than $T_{\text {in }}$. Also, $T_{w}$ follows the same trend as $T_{\text {in }}$ since the temperature of the water in the water tanks depends on the temperature of the HTF entering the heat exchanger. However, from the results obtained, Tin is always higher than $\mathrm{T}_{\mathrm{w}}$ due to the closed loop not operating in an ideal scenario as there is heat loss to the environment. Therefore, the heat transfer between the HTF and the water inside the tank is not $100 \%$ efficient. Table 1 shows the efficiency based on Eq. 2 mentioned above and solar radiation, $G_{b}$ averaging at $982 \mathrm{~W} / \mathrm{m}^{2}$ for the first three results and $710.3 \mathrm{~W} / \mathrm{m}^{2}$ for the last (for solar radiation data measured using a pyranometer). 
Table 1. Efficiency of each experiment

\begin{tabular}{|l|c|c|c|}
\hline HTF & $\mathbf{T}_{\mathbf{\text { out }}}\left({ }^{\circ} \mathrm{C}\right)$ & $\mathbf{T}_{\text {air }}\left({ }^{\circ} \mathrm{C}\right)$ & $\mathbf{\eta}_{\mathbf{T}}(\boldsymbol{\%})$ \\
\hline Water & 43 & 31.3 & $61.8 \%$ \\
\hline Saltwater at $10 \mathrm{~g} / \mathrm{L}$ & 43.2 & 31.7 & $61.9 \%$ \\
\hline Saltwater at $20 \mathrm{~g} / \mathrm{L}$ & 44.5 & 33.8 & $62.2 \%$ \\
\hline Saltwater at $20 \mathrm{~g} / \mathrm{L}$ with polystyrene & 46.3 & 36 & $62.4 \%$ \\
\hline Saltwater at $20 \mathrm{~g} / \mathrm{L}$ with acrylic foam & 34.1 & 33.3 & $66.2 \%$ \\
\hline
\end{tabular}

The efficiency calculation has been optimized to reflect more accurate results compared to the results previously presented in paper [1]. The main difference between the results of the previous paper and this one is that only stabilized experimental data have been considered in the efficiency calculation. By considering only the experimental results of a system which has been thermally stabilized eliminates cold start results of the system which affects the accuracy of efficiency calculation results. The thermal efficiency equation used previously optimized for a closed loop system with heat exchanger, while the efficiency calculation of this paper uses Eq. 2 which has been optimized for PVT systems with cylindrical heat exchangers. Comparing the results obtained, salt water at $20 \mathrm{~g} / \mathrm{L}$ with acrylic foam as pipe insulation is found to have the best thermal efficiency with a $4.4 \%$ improvement from using only water as HTF, a $4 \%$ improvement from using salt water at $20 \mathrm{~g} / \mathrm{L}$ without insulation and a $3.8 \%$ improvement from using polystyrene as insulation. Adding $10 \mathrm{~g}$ of salt per liter of water slightly improves the thermal efficiency by $0.1 \%$ and is observed to absorb heat faster when compared to water, taking only 30 minutes to reach the maximum temperature for $\mathrm{T}_{\text {in }}$ while water takes 40 minutes, as observed in Fig. 5. Hence, adding salt helps dissipate heat faster from the system but $10 \mathrm{~g} / \mathrm{L}$ is not enough for an effective heat transfer to the water tank. This is improved by increasing the salt concentration to $20 \mathrm{~g} / \mathrm{L}$ which yields an efficiency improvement of $0.3 \%$ and is able to achieve much higher $T_{\text {in }}$ temperatures while efficiently transferring the heat to the water tank, thus keeping low $\mathrm{T}_{\text {out }}$ temperatures. Compared to the $10 \mathrm{~g} / \mathrm{L}$ concentration, the $20 \mathrm{~g} / \mathrm{L}$ concentration improves $\mathrm{T}_{\text {in }}$ by $25.5 \%$.

\subsection{Voltage Characteristics}

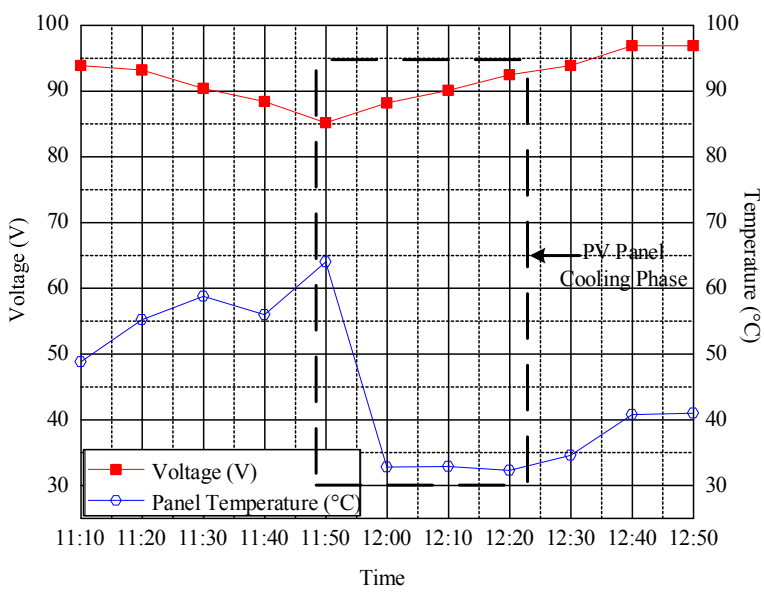


Fig. 10. PV voltage compared with PV temperature with cooling enabled.

Fig.10 shows an insight of how temperature affected the panel and the cooling period during which voltage is restored. From Fig. 10 it is observed that as the temperature of the PV panel increases, the voltage decreases. The voltage is restored by cooling the panel as highlighted by the dashed lines showing the PV panel's cooling phase. Table 2 below also shows that the voltage preserves its restored state even under lower sunlight radiation when under a low operating temperature after being cooled. The cooling phase is from around 11.50am until $12.20 \mathrm{pm}$.

Table 2. Voltage Supply compared with Solar Radiation and Temperature.

\begin{tabular}{|c|c|c|c|}
\hline Time & $\begin{array}{c}\text { Voltage } \\
(\mathrm{V})\end{array}$ & $\begin{array}{c}\text { Solar Radiation } \\
\left(\mathrm{W} / \mathrm{m}^{2}\right)\end{array}$ & $\begin{array}{c}\text { Panel } \\
\text { Temperature }\left({ }^{\circ} \mathrm{C}\right)\end{array}$ \\
\hline $11: 09: 57$ & 93.9 & 936 & 48.8 \\
\hline $11: 19: 57$ & 93.2 & 1005 & 55.2 \\
\hline $11: 29: 57$ & 90.4 & 1040 & 58.8 \\
\hline $11: 39: 57$ & 88.4 & 1037.1 & 56 \\
\hline $11: 49: 57$ & 85.2 & 1118.9 & 64 \\
\hline $11: 59: 57$ & 88.2 & 132.2 & 32.8 \\
\hline $12: 09: 57$ & 90.1 & 107.5 & 32.9 \\
\hline $12: 19: 57$ & 92.5 & 205.9 & 34.6 \\
\hline $12: 29: 57$ & 93.9 & 889.3 & 40.8 \\
\hline $12: 39: 57$ & 96.9 & 648.8 & 41 \\
\hline $12: 49: 57$ & 96.9 & 983.8 & \\
\hline
\end{tabular}

Considering the maximum and minimum voltage difference before and after cooling, a maximum improvement of $11.7 \%$ is noted when the panel's temperature is reduced by $24.1^{\circ} \mathrm{C}$. This enabled the PV panel to achieve $96.9 \%$ of its rated maximum peak voltage even under lower solar radiation conditions (measured using a pyranometer) which is not possible without cooling the panel. However, when the PV panel is reintegrated onto the Parabolic Trough as per the experimental setup of [11] for a general comparison, the thermal efficiency of the Parabolic Trough drops by almost $40 \%$.

\section{Conclusion}

Applying insulation to the concentrator pipe yielded higher thermal efficiencies. The acrylic foam performed better than the polystyrene insulation due to its advantageous thermal properties. Saltwater at $20 \mathrm{~g} / \mathrm{L}$ with acrylic foam as pipe insulation is found to have the best thermal efficiency with a $4.4 \%$ improvement from using only water as HTF, a $4 \%$ improvement from using salt water at $20 \mathrm{~g} / \mathrm{L}$ without insulation and a $3.8 \%$ improvement from using polystyrene as insulation. The cooling technique used for restoring the voltage drop of the PV panel due to heat in this research showed its potential as a hybrid PVT system where the heat build-up is reused or stored. The experiments are performed under no load as a study of the maximum voltage the panel reach compared to its rated voltage. 


\section{Acknowledgements}

This research is partially supported from the Taylor's University Flagship research grant TUFR/2017/001/01.

\section{References}

[1] Paul Kramer, Why are solar cookers still unpopular among development experts, Journal of Engineering Science and Technology, 5, no.1 75-84, (2010)

[2] M.F.HJ.Mohd. Amin, C.K.H. Chin, V.Garaniya, Application of alternatice energies in the australian offshore sector, Journal of Engineering Science and Technology, 11, no.9,1296-1310, (2016)

[3] D.F.A.L.Riza, S.I.U.H Gilani, M.S. Aris, Standalone photovoltaic system sizing optimization using design space approach: case study for residential lighting load, Journal of Engineering Science and Technology, 10, no.7,943-957 (2015)

[4] Vijayakumar G, Anita R, Photovoltaic based shunt active filter for power quality improvement using Icos $\phi$ theory, Journal of Engineering Science and Technology, 10, no.11,1422-1440, (2015)

[5] H. Machrafi, Enhancement of a photovoltaic cell performance by a coupled cooled nanocomposite thermoelectric hybrid system, using extended thermodynamics, Curr. Appl. Phys., 17, no. 6, pp. 890-911, 2017.

[6] K.Syed Jafar, B.sivaraman, Performance characteristics of parabolic solar collector water heater system fitted with nail twisted tapes absorber, Journal of Engineering Science and Technology, 12, no. 3, pp. 608-621, (2017)

[7] Aravind C.V., M. Al-Atabi, J. Ravishankar, A. Malik, Arkar, E. Ambikairajah, Eco-Tourism Sustainability through PV Technology: A Comprehensive View, Journal of Engineering Science and Technology, 8, no. 6, pp. 654-669, (2013)

[8] K. Fuji, Y. Shirai, Y. Mitani, M. Watanabe, T. Kawagoe, A. Shiota, A Research of Basic Energy Reduction Approach Using PV Power Smoothing EV Storage System and LED Simple Circuit for Create Green Innovation, Journal of Engineering Science and Technology, 2, no. 1, pp. 76-89, (2014)

[9] A. Shukla, K. Kant, A. Sharma, P. H. Biwole, Cooling methodologies of photovoltaic module for enhancing electrical efficiency: A review, Sol. Energy Mater. Sol. Cells, 160, pp. 275-286, (2017).

[10] R. Wang, W. Qu, J. Sun, H. Hong, An On-site Test Method for Optical Efficiency of Large-size Parabolic trough Collectors, Energy Procedia, 105, pp. 486-491, (2017)

[11] D. Kumar, S. Kumar, Simulation Analysis of Overall Heat Loss Coefficient of Parabolic Trough Solar Collector at Computed Optimal Air Gap, Energy Procedia, 109, no. pp. 86-93, (2017)

[12] D.Prakash, A review on heat dissipiating passive cooling techniques for residential buildings at tropical region, Journal of Engineering Sciences and Technology, 12, no.8, 2120-2140, (2017) 